\title{
Frequency of cancer among insulin-treated diabetic patients in Denmark
}

\author{
A. Green ${ }^{1}$ and O. M.Jensen ${ }^{2}$ \\ ${ }^{1}$ University Institute of Clinical Genetics, Odense, and ${ }^{2}$ Danish Cancer Registry, Copenhagen, Denmark
}

Summary. The total prevalent population of insulin-treated diabetic subjects (1499 patients) in Fyn County, Denmark, was followed for $8 \frac{1}{2}$ years (beginning 1 July 1973). All cases of cancer diagnosed during this period were identified by a record cross-check with the Danish Cancer Registry. In total, 45 and 37 cancer cases were identified among male and female patients, respectively, corresponding with observed/expected ratios of $1.37(p=0.03)$ and $1.08(p=0.65)$, respectively. Speci- fied for site, a significant excess of cancer of the pancreas was found (six cases observed vs 2.4 expected, $p=0.02$ ), but the excess was reduced by excluding cases where the cancer patient had diabetes as an early sign. Overall, no indications were found of an association between diabetes and cancer, whether in general or regarding particular cancer types.

Key words: Cancer, diabetes mellitus, epidemiology, registry.
Studies on the frequency of cancer in diabetic patient populations may reveal whether or not an association between cancer and diabetes exists. In particular, interest is focused on some specified cancer types. Among diabetic patients, cancer of the pancreas might represent a second manifestation of damage to the pancreas, leading to an increased risk of developing cancer. The frequency of cancer of the bladder may be increased because of the use of artificial sweeteners, and since diabetic individuals are generally advised to reduce smoking, their risk of developing cancer of the lung might be decreased. However, studies of the association between diabetes and cancer are scarce and inconsistent. In a longitudinal mortality analysis of about 4000 Norwegian diabetic patients, Westlund found indications of an increased incidence of cancer of the pancreas, of the digestive organs (except the stomach), and of leukaemia among men [1]. Other studies have demonstrated a decrease in cancer mortality [2]. British studies have found that the mortality caused by cancer of the bladder in diabetic patients is not increased [3, 4], and that overall cancer mortality is less, mainly due to the reduced number of deaths from cancer caused by smoking [4]. In a recent mortality study of a population of insulin-treated Danish diabetic patients, we found a slight, but statistically significant excess of deaths caused by cancer, evaluated on the basis of death certificates [5]. Kessler's review [6] includes a detailed account of the methodological problems concerned with studies on cancer and diabetes. In particular, mortality studies based on death certificates are subject to selection and information biases. Within the epidemiological framework, a valid alternative to the use of death certificates and mortality statistics is to study the occurrence of cancer, i.e. the incidence of cancer in a follow-up of a predefined group of diabetic patients.

To supplement our previous survey [5], we therefore studied the incidence of cancer in the follow-up of population-based, total sample of insulin-treated Danish diabetic patients.

\section{Subjects and methods}

\section{The diabetic patient group}

By means of insulin prescriptions during a 5-month period, and subsequent verification of diagnosis from medical records, the cross-sectional population of insulin-treated diabetic subjects from Fyn County, Denmark, was determined (as of 1 July 1973), as described earlier [7]. The final material, comprising 783 male and 716 female patients, has been estimated to be $\geqslant 98 \%$ complete and representative of the total Danish prevalent population of insulin-treated diabetic patients [7].

\section{Follow-up and identification of cancer cases}

The Danish Cancer Registry was founded in 1942 as the first nationwide cancer registry in the world and has been in operation ever since [8]. On a voluntary basis, the Registry receives notification from hospi- 
tal departments, pathology departments and departments of forensic medicine of all cases of malignant and related diseases when diagnosed. Furthermore, the Registry receives annually from the National Board of Health the death certificates for the total Danish population, which are then cross-checked with the Registry [8]. It is estimated that the register of cancer cases is approximately complete [9]. All information (personal data, site of the cancer, month and year of diagnosis, source of information, date and cause(s) of death) on all cases from 1943 through 1981 has now been recoded and computerized by the Registry.

Follow-up covered the period beginning 1 July 1973 to 31 December 1981. All diabetic patients who also had cancer were identified by correlating the patients' personal identification data with the total information in the Cancer Registry. All diabetic patients were followed until date of emigration or death, as described elsewhere [5], or to the end of the follow-up period. On this basis, the number of person-years at risk, observed among the patients during follow-up, was calculated for various 5-year age intervals within each sex. The Danish cancer incidence rates published that were applicable to the follow-up period [8] were used to estimate the expected number of cancer cases within each age and sex group. Because of the small numbers involved, both observed and expected numbers were grouped into broader categories according to age and sex, but the procedure employed inherently accounts for the age and sex composition of the patient population.

The strength of the association was evaluated by the relative incidence, i. e. the ratio between observed and expected numbers. The statistical significance was assessed by the statistic (number of observed - number of expected $)^{2} /$ (number of expected) that is assumed to follow the $\chi^{2}$-distribution with one degree of freedom. $p$-values $\geqslant 0.05$ (two-sided test) were considered non-significant. Test-based confidence limits $(95 \%)$ of the relative incidence were calculated as suggested by Miettinen [10].

Table 1. Observed and expected number of cancer cases (all types combined) during the follow-up period

\begin{tabular}{|c|c|c|c|c|c|c|}
\hline \multirow{2}{*}{$\begin{array}{l}\text { Age } \\
\text { group } \\
\text { (years) }\end{array}$} & & \multicolumn{2}{|c|}{ Cases of cancer } & \multirow{2}{*}{$\frac{\text { Observed }}{\text { Expected }}$} & \multirow{2}{*}{$\begin{array}{l}\text { Confí- } \\
\text { dence } \\
\text { limits } \\
(95 \%)\end{array}$} & \multirow[t]{2}{*}{$p^{\mathrm{a}}$} \\
\hline & & Observed & Expected & & & \\
\hline \multirow[t]{2}{*}{$0-54$} & Men & 10 & 4.90 & 2.04 & $1.11-3.74$ & 0.02 \\
\hline & Women & 6 & 5.36 & 1.12 & $0.50-2.49$ & NS \\
\hline \multirow[t]{2}{*}{$55+$} & Men & 35 & 27.87 & 1.26 & $0.90-1.76$ & NS \\
\hline & Women & 31 & 28.99 & 1.07 & $0.75-1.53$ & NS \\
\hline \multirow[t]{2}{*}{ Total } & Men & 45 & 32.77 & 1.37 & $1.03-1.83$ & 0.03 \\
\hline & Women & 37 & 34.35 & 1.08 & $0.77-1.51$ & NS \\
\hline
\end{tabular}

a Two-sided

\section{Results}

The record cross-cheek identified 45 male and $37 \mathrm{fe}$ male cases of cancer, diagnosed within the follow-up period. For the male cases, this corresponded with 45 patients, but only 36 female patients were identified because one had two diagnoses of cancer (of the colon 30 years after the onset of diabetes and of the skin 35 years after the onset of diabetes).

Table 1 shows the observed and expected number of cancer cases (all types combined). In total, the male relative incidence was 1.37 , which is marginally significantly increased $(p=0.03)$; the excess was restricted to men $<55$ years of age (relative incidence $=2.04$, $p=0.02$ ), whereas the relative incidence for the older age group was not significantly increased. The female relative incidence was not significantly increased within age groups or as a total.

Table 2 shows the cancer cases according to cancer site. Due to the small numbers, the age and sex groups were combined (but with adjustment for these factors as described above). Apart from cancer of the breast (only women), the relative incidence of all types was slightly increased in the diabetic population, but only cancer of the pancreas was significantly so $(p=0.02)$. However, in two patients, diabetes was most likely the early sign of cancer, and after excluding these two patients from the analysis, the relative incidence becomes 1.69 , which is not a significant increase $(p=0.29)$. Of the four remaining patients in this group, cancer of the pancreas developed in two men ( 7 and 37 years after the onset of diabetes, respectively) and in two women ( 6 and 8 years after the onset of diabetes, respectively).

\section{Discussion}

Because the diabetic patient population [7] and the registration of cancer cases in the Danish Cancer Registry $[8,9]$ were virtually complete, we believe that all cases of cancer were identified within the limits of our study. Furthermore, since the study was based on the incidence

Table 2. Observed and expected number of cancer cases, grouped according to cancer site (male and female cases combined)

\begin{tabular}{|c|c|c|c|c|c|}
\hline \multirow[t]{2}{*}{ Site of cancer } & \multicolumn{3}{|c|}{ Cases of cancer } & \multirow{2}{*}{$\begin{array}{l}\text { Confidence } \\
\text { limits } \\
(95 \%)\end{array}$} & \multirow[t]{2}{*}{$p^{\mathrm{a}}$} \\
\hline & Observed & Expected & Expected & & \\
\hline Stomach, colon, rectum (excluding sarcoma) & 17 & 12.98 & 1.31 & $0.81-2.11$ & NS \\
\hline Pancreas (excluding sarcoma) & $6^{\mathrm{b}}$ & 2.37 & 2.53 & $1.17-5.47$ & 0.02 \\
\hline Respiratory system & 12 & 9.56 & 1.26 & $0.71-2.24$ & NS \\
\hline Cervix uteri (women only; excluding sarcoma) & 3 & 2.04 & 1.47 & $0.48-4.50$ & NS \\
\hline Bladder & 4 & 3.80 & 1.05 & $0.41-2.68$ & NS \\
\hline All other sites & 30 & 25.95 & 1.16 & $0.81-1.67$ & NS \\
\hline
\end{tabular}

\footnotetext{
a Two-sided

b Two cases (one man and one woman) were diagnosed $<5$ years from onset of diabetes
} 
of cancer, the biases inherently associated with the use of death certificates $[2,6]$ have been eliminated.

In our study it was important to take into account the cancer cases in which diabetes was a symptom of cancer and not a pre-existing condition. This is particularly relevant for cancer of the pancreas. With correction for this, we found no overall excess of the incidence of cancer during follow-up of the diabetic patients, although there was a slightly increased incidence among younger male patients. No individual type of cancer seemed to be associated with diabetes; accordingly, we were not able to confirm the finding from Norway of an increased incidence of cancer of the pancreas [1], and that from the United Kingdom of a reduced incidence of cancer of the respiratory system [4]. It should be noted, however, that whereas the diabetic population in the British study seemed to smoke less than the population in general [4], an interview study of a subset of the present patient group revealed that our patients had smoking habits similar to those of the general Danish population (Sjølie, unpublished observation).

The results of the present study concerning the incidence of cancer is in contrast to the finding from a mortality study of the same patient group [5] in which a small, but statistically significant excess of deaths caused by cancer was observed on the basis of information from death certificates [5]. One possible explanation is that the medical history of diabetic patients is in general wellknown to the medical profession, and this might imply a higher than average likelihood of having cancer, if present at death or previously recorded on the death certificate. Alternatively, the prognosis for patients with both diabetes and cancer might be worse than for patients with cancer but without diabetes. Regardless of what is correct, the discrepancy underlines the potential biases associated with studies based on death certificates only.

Overall, we found no association between insulintreated diabetes and the risk of developing cancer. However, the analysis is based on a small number of cancer cases, and we cannot exclude the possibility that subgroups of our patients may run a higher risk than expected, because the present patient population is most likely heterogeneous with respect to clinical characteristics [11]. In fact, the marginally significant excess among male patients is due to a higher than expected number of cases of cancer in the age group $<55$ years (Table 1 ), and the diabetic patients observed in this age group are probably more likely to have true Type 1 (insulin-dependent) diabetes compared with the patients in the older age group [11]. On the other hand, no similar trend was observed for the female diabetic patients (Table 1) and, furthermore, the small numbers make detailed analysis impossible. We intend to perform a similar study after an extended follow-up period so that the correspondingly increased observation time will permit more detailed analysis, including stratification of the patients according to their clinical characteristics.

\section{References}

1. Westlund K (1969) Mortality of diabetes. Life Insurance Companies' Institute for Medical Statistics at the Oslo City Hospital. Report No.13. Universitetsforlaget, Oslo, pp 29-30, 70

2. Fuller JH, Elford J, Goldblatt P, Adelstein AM (1983) Diabetes mortality: new light on an underestimated public health problem. Diabetologia 24: 336-341

3. Armstrong B, Doll R (1975) Bladder cancer mortality in diabetics in relation to saccharin consumption and smoking habits. $\mathrm{Br} \mathbf{J}$ prev soc Med 29: 73-81

4. Armstrong B, Lea AJ, Adelstein AM, Donovan JW, White GC, Ruttle S (1976) Cancer mortality and saccharin consumption in diabetics. Br J prev soc Med 30: 151-157

5. Green A, Hougaard P (1984) Epidemiological studies of diabetes mellitus in Denmark. 5. Mortality and causes of death among insulin-treated diabetic patients. Diabetologia 26: 190-194

6. Kessler II (1971) Cancer and diabetes mellitus. A review of the literature. J Chron Dis 23: 579 600

7. Green A, Hauge M, Holm NV, Rasch LL (1981) Epidemiological studies of diabetes mellitus in Denmark. II. A prevalence study based on insulin prescriptions. Diabetologia 20:468-470

8. Danish Cancer Registry (1982) Incidence of cancer in Denmark 1973-1977. Danish Cancer Registry, Copenhagen

9. Holm NV, Hauge M, Jensen OM (1982) Studies of cancer aetiology in a complete twin population: breast cancer, colorectal cancer and leukaemia. Cancer Surveys 1:17-32

10. Miettinen O (1976) Estimability and estimation in case-referent studies. Am J Epidemiol 103: 226-235

11. Green A, Hougaard P (1983) Epidemiological studies of diabetes mellitus in Denmark. 4. Clinical characteristics of insulin-treated diabetes. Diabetologia 25: 231-234

Received: 9 July 1984

and in revised form: 24 January 1985

Dr. Anders Green

University Institute of Clinical Genetics

J.B. Winsløwsvej 17

DK-5000 Odense C

Denmark 